\title{
Asymptomatic Vesicoperitoneal Fistula After Pelvic Radiation: A Case Report and Literature Review
}

\author{
(D) Hannah Kay1, (D) Pooja Srikanth1, (D) J. Stuart Wolf2, (D) E. Charles Osterberg ${ }^{3}$ \\ 1 Dell Medical School, Austin, Texas, US \\ 2Dell Medical School, Department of Surgery and Perioperative Care, Austin, Texas, US \\ ${ }^{3}$ Chief of Urology, Dell Seton Medical Center at the University, Austin, Texas, US
}

\begin{abstract}
Vesicoperitoneal fistula (VPF) is a rare complication of pelvic radiation. Patients with VPF often present with signs and symptoms of urinary ascites. Few published reports on patients presenting with VPF for $>10$ years following pelvic radiation exist. This case report describes an incidentally-found VPF in a patient 12 years after pelvic radiation for cervical cancer. The patient underwent OR cystoscopy for persistent hematuria, which revealed a $3-\mathrm{cm}$ hole in the bladder with protrusion of abdominal contents. Thus, this case demonstrates that VPF may present insidiously in any post-pelvic radiation patient, regardless of duration after radiation.
\end{abstract}

Keywords: Radiation cystitis, fistula, vesico-peritoneal fistula

\section{Introduction}

Radiation cystitis is inflammation and destruction of the urinary bladder secondary to radiation (1). It is a known complication in patients with cervical cancer. In patients with radiation cystitis, 3.2\% present acutely (within 6 months of treatment), and $80 \%$ present chronically (2-4 years after treatment). Further progression may lead to radiation-induced bladder fistula typically after a minimum 4 years after initial radiation treatment. Radiation cystitis often presents as hemorrhagic cystitis, and it is treated initially with bladder lavage and clot evacuation, followed by bladder instillations with hyaluronic acid coupled with hyperbaric oxygen therapy to promote angiogenesis (2). Although these procedures show promising results, they are neither widely available nor financially feasible (3). Postradiation vesicoperitoneal fistula (VPF) are incredibly rare, and all cases in literature have presented with urinary ascites. Herein, we report an incidentally discovered VPF in a patient who received pelvic radiation for cervical cancer.

\section{Case Reports}

We report the case of a 56-year old female with a history of stage IIB squamous cell carcinoma of the cervix diagnosed and treated in 2008 with external beam radiation therapy (43.2 Gy, AP/PA to 3.5 Gy) to the whole pelvis and intracavitary brachytherapy with cesium 137. Patient gave her consent prior to the creation of this case report. She had intermittent vaginal bleeding for over 10 years and underwent operative vaginal and cervical biopsies that were both negative for malignancy in 2019. She began consulting a urologist in January 2020 for management of persistent hemorrhagic cystitis. Pelvic computed tomography (CT) at that time showed a large amount of abnormal material in the bladder lumen consistent with hematoma. There was no evidence of vesicovaginal fistula. She underwent an uncomplicated cystoscopic bladder fulguration in January 2020 and continued to experience painless hematuria and underwent a single session of hyperbaric oxygen therapy in March 2020. CT at that time showed no evidence of fistula. She was suggested to have a second fulguration in June 2020; this time, she presented only with hematuria. She had no complaints regarding abdominal pain, nausea, dysuria, and difficulty in urinating. Vital signs were within normal limits as well as the physical exam but for mild suprapubic tenderness. Her abdomen was soft, nontender, and nondistended. Pelvic exam was deferred. Preoperative lab values were as follows: white blood cell count of $7200 \mathrm{~mm}^{-3}$, hemoglobin titer of $8.9 \mathrm{~g} / \mathrm{dL}$, platelets

Correspondence: Hannah Kay BA, Dell Medical School, Austin, Texas, US

Phone: $512-348-1000$

E-mail: hannah.kay@utexas.edu ORCID-ID: orcid.org/0000-0003-2085-9202

Received: 12.01.2021

Accepted: 09.06.2021

Cite this article as: Kay H, Srikanth P, Wolf JS, Osterberg EC. Asymptomatic Vesicoperitoneal Fistula After Pelvic Radiation: A Case Report and Literature Review. J Urol Surg 2021;8(3):217-219.

${ }^{\circ}$ Copyright 2021 by the Association of Urological Surgery / Journal of Urological Surgery published by Galenos Publishing House. 
count of 141,000 $\mathrm{mm}^{-3}$, blood urea nitrogen (BUN) titer of 10 $\mathrm{mg} / \mathrm{L}$, and creatinine $(\mathrm{Cr})$ titer of $1.0 \mathrm{mg} / \mathrm{dL}$.

During OR cystoscopy, her bladder was noted to be widely necrotic and a $3-\mathrm{cm}$ hole was discovered at the dome with protrusion of the abdominal contents into the bladder. The procedure was switched to an open exploratory laparotomy with complex cystorrhaphy using local advancement perivesicular flaps (Figure 1). The repair was water tight to $100 \mathrm{cc}$ and her cystogram on postoperative day 9 showed no extravasation (Figure 2). However, at postoperative day 12, she presented to the emergency department with severe abdominal pain and shortness of breath. Imaging revealed bladder rupture. During emergent re-exploration, urine was found in the pelvis and her bladder was repaired again utilizing both perivesicular and omental flaps. Repeat cystogram demonstrated an intraperitoneal bladder leak and an open bilateral ureteral ligation with placement of percutaneous nephrostomy tubes was decided as the appropriate surgical technique.

\section{Discussion}

Although certain types of fistulas are common after procedures in gynecologic oncology, VPF is incredibly rare after radiation (3).

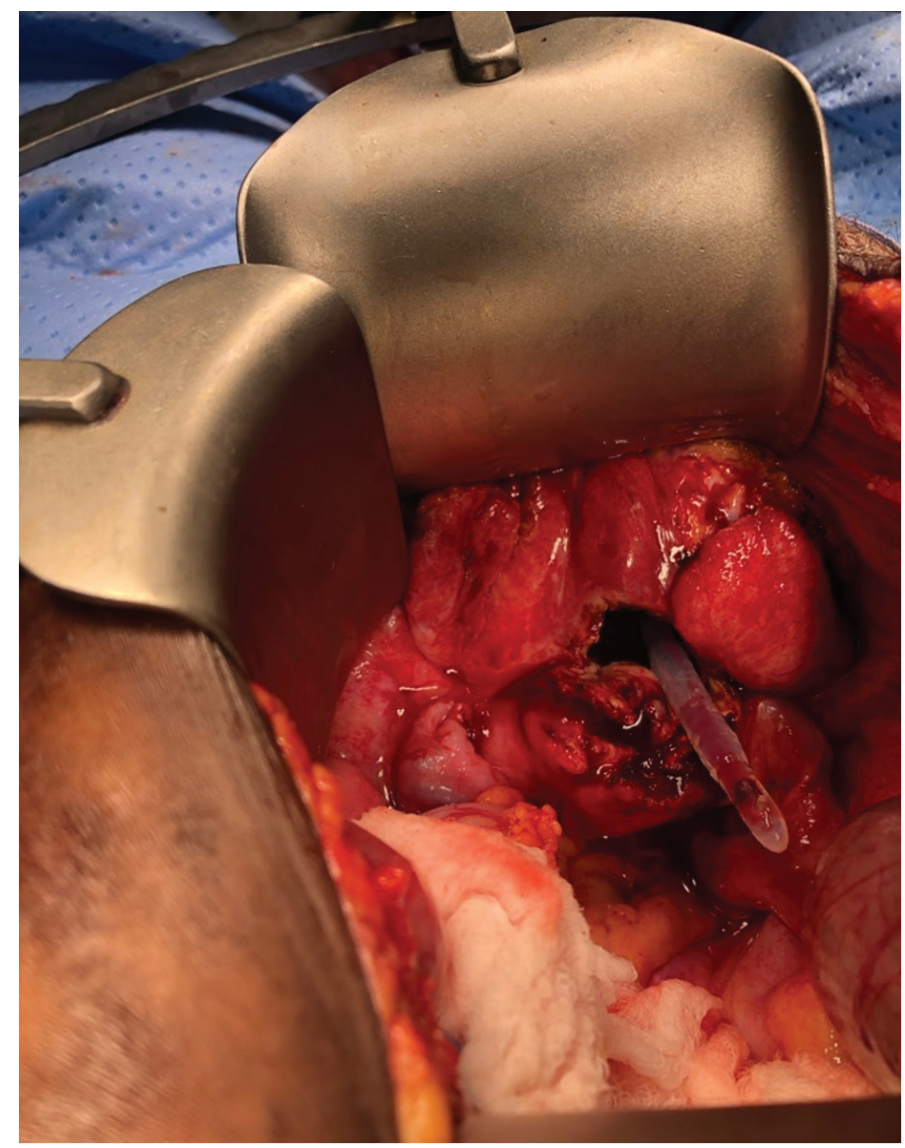

Figure 1. Catheter protruding through a $3-\mathrm{cm}$ hole at the dome of the bladder with entry into the peritoneum

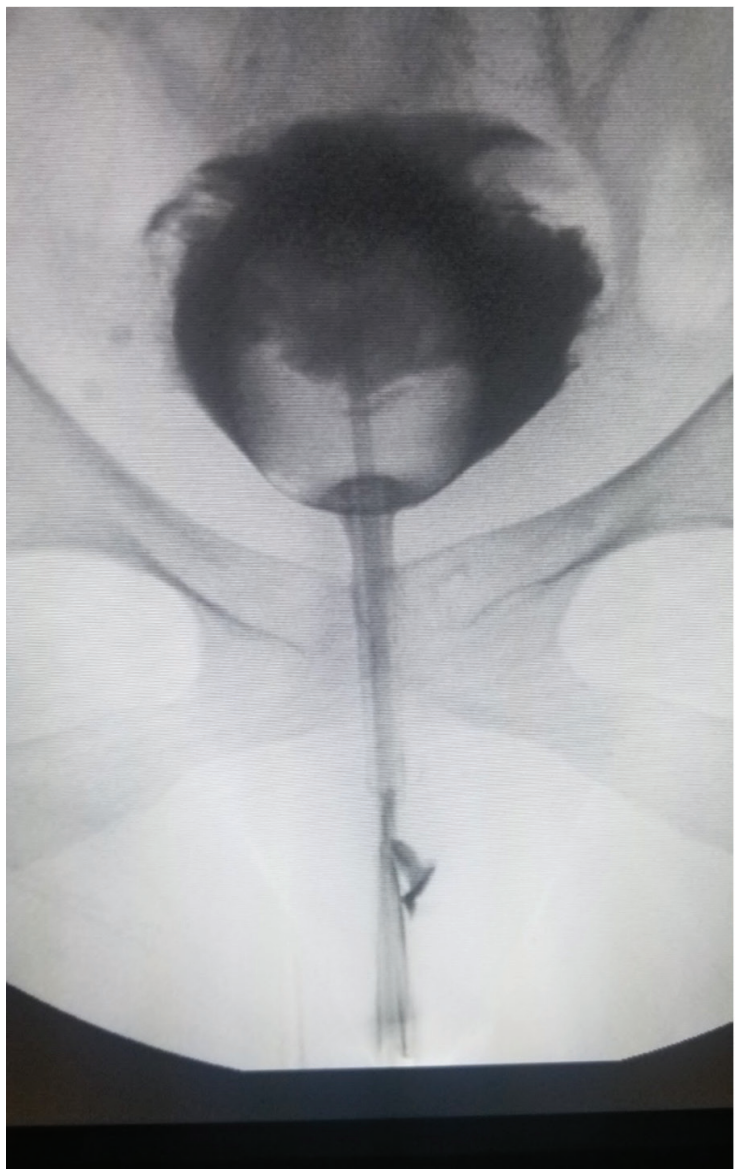

Figure 2. Retrograde urethrogram on POD\#10 (no extravasation)

Regardless of etiology, patients with VPF commonly present with generalized, dull, and gradually increasing abdominal pain, abdominal distension, nausea, vomiting, and dysuria (4-6). Lab values often show elevated blood and ascitic BUN and $\mathrm{Cr}$, reflective of peritoneal resorption of urine (7). The diffusion of

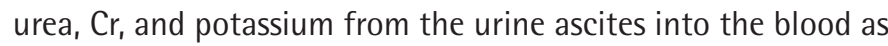
well as sodium diffusion in the opposite direction (from serum to ascites) can lead to pseudorenal failure (8). There are two reported cases of VPF following pelvic radiation alone $(7,9)$ and a third case following radiation and salvage prostatectomy (10). The duration of vesicovaginal fistula formation after pelvic radiation has been reported up to 30 years $(3,11)$, but only one case of VPF presenting $>10$ years after radiation has been reported in literature (7). The risk of the formation of fistula increases in patients with a history of pelvic radiation undergoing instrumentation, particularly complex procedures (12). Our patient did undergo a bladder fulguration five months prior to her VPF diagnosis. Our case was unique as the patient did not develop symptomatic urinary ascites despite the presence of a 3-cm VPF; she also had fistula development 12 years after undergoing pelvic radiation. An ischemic perforation and/or fistula formation is more likely after fulguration in a patient that has previously received pelvic radiation therapy. Despite 
the asymptomatic nature of this patient's course regarding her fistula, the fact that her medical history includes pelvic radiation as well as more recent bladder instrumentation does weaken the claim that her fistula was a spontaneous event and must be considered when reviewing her case. One possible explanation for her asymptomatic initial presentation is that because of the size of her fistula, urine could pass into and out of her bladder in a way that prevented the buildup of ascites.

Plain film cystography often provides definitive diagnosis of the fistula and is useful for assessing the size and viability of surrounding tissues, thereby determining management method (13). Our patient had no abdominal pain, dysuria, or findings of pseudorenal failure on labs. Her abdominal imaging was consistently negative for fistula up to three months prior to her second scheduled fulguration in the OR. A VPF of $<1 \mathrm{~cm}$ can be managed conservatively with indwelling catheter and constant bladder decompression for 3-5 weeks to allow for tract closure (4). For a VPF of $>1 \mathrm{~cm}$, laparoscopic closure or open cystorrhaphy should be considered. Regardless of the type of repair, patients should be followed with cystogram 10-14 days postoperatively to assess for healing and persistent fistula (14). Based on our unique case, VPF must be considered in all patients after receiving pelvic radiation therapy for cervical cancer, especially those with radiation cystitis, regardless of lack of abdominal symptoms.

\section{Ethics}

Informed Consent: Patient gave her consent prior to the creation of this case report.

Peer-review: Externally and internally peer-reviewed.

\section{Authorship Contributions}

Surgical and Medical Practices: E.C.O., J.S.W., Concept: H.K., E.C.O., J.S.W., Design: H.K., Data Collection or Processing: H.K., E.C.O., J.S.W., Analysis or Interpretation: H.K., P.S., E.C.O., J.S.W., Literature Search: H.K., P.S., Writing: H.K., P.S., E.C.O., J.S.W.

Conflict of Interest: No conflict of interest was declared by the authors.
Financial Disclosure: The authors declared that this study received no financial support.

\section{References}

1. Horan N, Cooper JS. Radiation Cystitis And Hyperbaric Management. 2021 Jul 18. In: StatPearls [Internet]. Treasure Island (FL): StatPearls Publishing; 2021 Jan.

2. Liem X, Saad F, Delouya G. A Practical Approach to the Management of Radiation-Induced Hemorrhagic Cystitis. Drugs 2015;75:1471-1482.

3. Zoubek J, McGuire EJ, Noll F, DeLancey JO. The late occurrence of urinary tract damage in patients successfully treated by radiotherapy for cervical carcinoma. J Urol 1989;141:1347-1349.

4. Ananna MA, Ahmed MA, Haque WMM, Ahmed Z. Urinary Ascites: Cryptic Presentation of Unrecognized Urinary Bladder Injury. Birdem Med J 2012;2:60-62.

5. Ilktac A, Ersoz C, Dogan B, Kalkan S. Mesh related vesico-peritoneal fistula presenting with urinary ascites: A case report. Urol Case Rep 2018;23:3940.

6. Khan MA, Zargar SA, Javid G, Khan BA, Shah AH, Gulzar GM, Sodhi JS. Vesicoperitoneal fistula--an unusual cause of tense ascites. Indian J Gastroenterol 2007;26:138-139.

7. Shi F, Wang T, Wang J, Hui B, Chai Y, Wang J, Liu Z. Peritoneal bladder fistula following radiotherapy for cervical cancer: A case report. Oncol Lett 2016;12:2008-2010.

8. Al-Mandeel $\mathrm{H}$, Qassem A. Urinary ascites secondary to delayed diagnosis of laparoscopic bladder injury. J Minim Access Surg 2010;6:50-52.

9. Fujikawa K, Yamamichi F, Nonomura M, Soeda A, Takeuchi H. Spontaneous rupture of the urinary bladder is not a rare complication of radiotherapy for cervical cancer: report of six cases. Gynecol Oncol 1999;73:439-442.

10. Parker R, Janjan N, Selch M. Radiation Oncology For Cure And Palliation, 1st ed. Berlin: Springer; 2011.

11. Angioli $R$, Penalver $M$, Muzii $L$, Mendez $L$, Mirhashemi $R$, Bellati $F$, Crocè $C$ Panici PB. Guidelines of how to manage vesicovaginal fistula. Crit Rev Oncol Hematol 2003;48:295-304.

12. Berek JS, Howe $C$, Lagasse $L D$, Hacker NF. Pelvic exenteration for recurrent gynecologic malignancy: survival and morbidity analysis of the 45-year experience at UCLA. Gynecol Oncol 2005;99:153-159.

13. Morey AF, Brandes S, Dugi DD 3rd, Armstrong JH, Breyer BN, Broghammer JA, Erickson BA, Holzbeierlein J, Hudak SJ, Pruitt JH, Reston JT, Santucci RA,

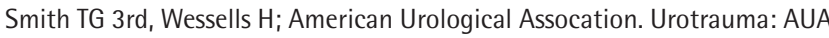
guideline. J Urol 2014;192:327-335.

14. Yeung LL, McDonald AA, Como JJ, Robinson B, Knight J, Person MA, Lee JK, Dahm P. Management of blunt force bladder injuries: A practice management guideline from the Eastern Association for the Surgery of Trauma. J Trauma Acute Care Surg 2019;86:326-336. 